\title{
University English Teaching reformation and countermeasures under the background of informationization
}

\author{
Xiping LIU \\ Chengde TV University \\ Chengde,Hebei 067000, China
}

\author{
Xiaodong SUN \\ Chengde TV University \\ Chengde,Hebei 067000, China
}

\begin{abstract}
With the development of society, college English teaching reform is imperative. In this paper combined with the "course requirements" in transforming teaching ideas, changing teaching mode, reforming the examination, evaluating system and other aspects of the proposed reform measures new requirements are proposed and the counterpart measures are put forward in the appropriate teaching methods, teaching environment and teaching philosophy and so on.
\end{abstract}

Keywords- university English: information; teaching reform; reform measures

\section{INTRODUCTION}

Significance of informationization in college English teaching

Traditional college English teaching is a simple form to teach students for whom to receive knowledge is very passive. Language learning focuses on developing the ability but the passive receive of knowledge is not conducive to inspire students to think on their own and the actual use of language would be difficult to get good developed and improved, which is not conducive to the effective implementation of English education. In today's information age, this way of teaching to the learner can neither cultivate creative talents adapt to the times demand, can nor effectively achieve the practicality of language learning but it can only impart some basic knowledge of the content. To adapt language teaching reform, using full of advanced information technology, integrating a variety of resources can help to achieve teaching informationization, which has profound significance and impact for higher education reform.

First, the teaching informationization is conducive to achieve the practicality meaning of language teaching. The traditional English teaching regards English as a kind of knowledge to spread, while ignoring the language was originally just a communication tool, thus the practicality of meaning in English is neglected and it is difficult to cultivate students' interest in learning English. With the use of multimedia and other means, informationized teaching methods can vividly demonstrate English charm and practicality in real life, creating a atmosphere of learning English and attract students with an interest in the exchange at the input to the students knowledge, stimulating further positive student learning autonomy.

Secondly, the teaching informationization riches teaching modes, and improves teaching effectiveness. Various forms of informationized teaching combined teaching and learning is to change passive learning psychology and model, enhancing exchanges and cooperation among students and teachers, and to effectively resort to abstract knowledge in the form of sound and picture image so blunt informative content becomes concrete, vivid, deepened the impression of student learning, thus improve the efficiency of student learning, and strengthen the effectiveness of teaching.

\section{SitUATION ANALYSIS ON COLLEGE ENGLISH TEACHING RESOURCES}

\section{A. the number of rapid growth, the carrier forms}

In recent years, schools and departments at all levels have increased investment in informationized college English teaching software and hardware, such as the construction of language lab, development of network voicelearning courses, buy online English learning software to create online learning platform, etc. These advanced network technology provides a vast amount of various forms of informationized college English teaching resources. However, there is no fundamental change in the teaching philosophy and mode for lacking teachers' necessary guidance, resulting in most language learners still mainly rely on traditional paper-based learning resources and weak ability of independent exploration and utilization of diverse teaching resources.

\section{B. lack of student participation, distributed widely dispersed}

Most existing English teaching resources created and provided by experts or teachers, lacking learners' participation, the understanding, interpretation, criticism and innovation of the content of teaching from learners, and resources interaction. It is difficult to stimulate the spirit of innovation and critical awareness of learner autonomy in learning to lack of interaction between learners and teaching resources. In addition, the construction of informationized 
college English teaching resource base is weak, developing a single system, multi-stakeholder mechanisms is not yet established, redundant construction, serious lack of effective co-ordination mechanisms, information management level is not high, the lack of teaching resources in the design and construction of a reasonable standard, it is difficult to create synergy, too scattered distribution of resources, lack of resource sharing, and low efficiency. Whether teachers or students, their IT knowledge structure can not fully meet the requirements of the development of informationized college English teaching, especially the ability to reasonably converged IT and English courses were not enough, the lack of the ability to innovate technology in language teaching, leading to low utilization of college English teaching resources, and even cause information equipment or resources idle situation. In addition, awareness of cooperative learning among teachers is still relatively weak: the teacher did not realize the importance of sharing information, and a strong sense of competition even let some teachers think that sharing teaching resources is against their own advantage. The college English teaching resources is difficult to raise the level of informationization.

\section{COLLEGE ENGLISH TEACHING REFORM MEASURES}

\section{A. foster awareness of informationization}

Living in the world of informationization and facing intense employment environment, we must first establish a culture of informationization awareness, willing, eager to accept the foreign culture. From the input of Western Europe informationization and minorities informationization, nurture culture-loving English enthusiasm. Strengthen student communication and exchange of information as much as possible to intensify concept of the national development, the harmonious development of the nation, especially students of ethnic regions, because they have different cultural backgrounds, so they realize that outside of the family culture Western culture and other ethnic cultures is today an important part of cultural knowledge, we should respect its value, its essence, drawing criticism.

\section{B. changing role of teachers}

In the teaching process, the implementation of the "students" as the main teaching, but the role of the teacher is still critical. A considerable part of the teacher in teaching, more or less by the traditional teaching model, methods bondage, their role did not change. In traditional English teaching, teachers play a major organizer of teaching, curriculum designers, knowledge transfer those roles, resource providers, macro managers. In this mode of teaching, students learn passively, lack of awareness of selfstudy, failed to fully stimulate enthusiasm for learning, so the poor effect is poor. In this regard, changing the role of teachers, for teachers teaching in play organizers, curriculum designers, while a knowledge builders, teaching evaluation who were targeting, resource providers, difficulty helpers, imparting knowledge, supervision, facilitator, researchers, such as guide for the integrated role. By changing role of teachers reforms, allows students to enhance the actual ability to use English, thereby increasing the weight for the employment of foreign language proficiency test.

\section{C. focus on teachers' professional development}

Professional development of teachers is to ensure that the premise of teaching quality. Training to adapt to high-quality and fine professional background information under College English teacher is imperative. This can be the success stories from abroad, such as pre-service teacher courses in the United States opened a informationization course, which has a great inspiration to set up our university teacher education courses. Teacher's words and deeds should influence the students. In this regard, the education department or agency may have set up a separate "information content" courses for teachers to help teachers understand the different groups at home and abroad, cultural similarities and differences of race, popular culture knowledge, mutual recognition and respect on the basis of a correct view and applied to college English teaching practice. At the same time it helps teachers examine their attitudes towards informationization in informationbased education role. In today's era of cultural diversity, the teacher should become the information understanding indigenous knowledge imparters, information education environment and research actor. Thus in the background of informationization, teachers constantly enrich the knowledge, enrich the teaching content, improve college English teaching, as a solid foundation for students of English employment, and play college English teachers' role in promoting good harmony.

\section{D. grade teaching need to meet the needs of students}

With the development of higher education and college enrollment, different universities, students of different faculties, for historical reasons or because of individual differences, geographical factors, their English is uneven, but the traditional model of large classes and traditional teaching methods are no longer suitable for different level and stage of the student, so the traditional English teaching mode is in need of reform. Different students in English listening, speaking, reading and writing basic skills are not the same, leading to different students have different needs to improve their English skills which requires English teaching mode is designed to maximize meet the needs of students learning English. In this regard, combined with the reality of students, it can be ranked by English proficiency test, adopt the model of College English teaching, but different from the traditional hierarchical teaching. That is according to the students, the use of a "1 to 2 grade teaching required courses" and "a selection of elective courses" as the subject, supplemented by "self-learning task." Teachers regularly test student learning, the implementation of cross-level crosselimination replacement system, the test of outstanding students into a class to learn English proficiency level, whereas the opposite. Graded teaching can help classes to quite same students' level, teaching becomes rather easy, but also make students more confident and improve student interest in learning. 


\section{E. Textbook Reform and Innovation}

Textbooks are an important resource for the implementation of English teaching, thus teaching innovation in some way is related to the effect of the whole teaching. How to ensure that college English teaching "information" of gold content, reflecting the characteristics of the discipline of informationization is an important issue. According to statistics, the Western Europe and many developed countries schools for students have set up an informationization courses, as many American schools are opened: informationization education and research, informationization education philosophy of education in a pluralistic society, there are some Schools offer courses related to non-Western cultures, to introduce students to the cultural background of Asia, Africa, South America and other countries, geography, and political economy. In terms of materials compiled, as far as possible to consider, a representative of the content or information related to the latest incident involving the preparation to go abroad. Textbooks should also be considered applicable to ethnic groups of students, according to their national characteristics to write one of the sections of the culture, that classification is written using the classification, staging updates to textbook "diversity" to reflect the contents of the "diversity" . This allows the teaching innovation, advance with the times, realistic, and better knowledge to provide quality resources for college English teaching, better learning for students to be able to integrate knowledge and social development, thus contributing to students' employment.

\section{F. $\quad$ stimulate students a positive learning motivation}

Motivation, simply put, is to promote the underlying causes of student learning activities to motivate, powerful engine guidelines of student learning. Good motivation, enable students to enhance English learning into a virtuous cycle trend. Thus, the English teaching reform must also be considered beneficial to stimulate students' positive motivation. The main motivation of students learning English in the past is for the exam, get a diploma, find good jobs and other external motivation while reform should guide or encourage students' motivation to learn gradually converted from external to internal motivation and results for the purpose of making Students increasingly receptive to new college English teaching mode or method, and because the new teaching mode or method of production increase interest in learning English, so that the internal motivation to learn English to get their relative increase, significant progress in English learning, passion rising, promote the results generated motion.

\section{G. Reform and Innovation Evaluation Mechanism}

Reform from the traditional summative assessment to formative assessment. Summative assessment, the lack of an objective and impartial evaluation of the teaching process, only concerned about students at a specific time and place of the assessment of the state, which neither is not conducive to the key information for teachers to understand students whether master knowledge and skills training, nor is not conducive to Teachers monitor students' academic progress, and thus have a negative impact on the teacher's teaching schedule. In contrast, formative assessment is not only for the students knowledge of the language, but also on language skills, learning interest, emotion and strategies in order to achieve the monitoring of students' knowledge and skills to master the progress and extent of purpose. Specifically used: test evaluation, including academic achievement test (test whether students master the syllabus); Proficiency Test (Test of English level of students, schools can customize the actual outline); diagnostic tests (found in students' problems, to help teachers understand the students in a timely manner, FAQ, adjust lesson plans, etc.). Non-test assessment, including classroom observation (language use, activity participation, etc.); portfolios (student, and teachers to participate in monitoring their own learning and reflection, cultivate self-learning ability); interviews (to understand the students learning attitude, emotion, learning strategies and language knowledge

Etc.); Implementing evaluation (refer to student life and learning situations, through the observation of the students to complete the actual job performance, rely on the professional judgment of teachers on students' academic achievement evaluation methods of teaching overall judgment). Thus, the reform of the evaluation mechanism is an important part of college English teaching reform.

\section{CONCLUSIONS}

Reform of college English teaching is a process rather than a task. This means that reforms are under development and changes in the social environment of continuous innovation and exploration, to abandon traditional methods behind the development of the times, to inherit and carry forward its best parts, combined with modern technology constantly updated, making college English teaching to better serve society. We must constantly sum up experience in teaching practice, improve the teaching model for the society to cultivate more excellent English language skills.

\section{References}

[1] Li Xin College English Teaching and countermeasures [J] China Science and Technology Information, 2008,04: 227-228.

[2] Feng Xia Resource Optimization Strategies in college English teaching context of information technology $[\mathrm{J}]$ Liaoning Educational Administration Institute, 2013,06: 57-60.

[3] Yang Yuan thinking multicultural background of college English teaching reform $[\mathrm{J}]$ Chongqing University of Science and Technology (Social Sciences), 2010,06: 199-201.

[4] Yu Boying to the way of college English teaching under the Integrated Framework [J] Foreign Language Education, 2010,06: 7780.

[5] Hu Chunfang network backdrop of college English teaching reform [J] Science and Education Guide (in Xunkan), 2012,02: 57 + 73.

[6] Li Chunyan, Wang Shiqing college English teaching background in network problems and countermeasures $[\mathrm{J}]$ Jining Teachers College, 2012,02: 87-90.College English Teaching

[7] Yang Xiaohui under the New Curriculum [J] Lanzhou Institute of Education, 2013,09: 55-56.

[8] Yang Yuan college English teaching multicultural background [J] education and occupation, 2013,29: 147-148. 